\title{
NEGOTIATING STRATEGY: IMPORTANCE OF THE MARKET DEFINITION
}

\author{
Kęstutis PELECKIS ${ }^{1 *}$, Valentina PELECKIENE ${ }^{2}$, Kestutis PELECKIS ${ }^{3}$, Edita LEONAVIČIENE ${ }^{4}$ \\ ${ }^{I}$ The Department of Economics Engineering, Faculty of Business Management, \\ Vilnius Gediminas Technical University, Saulettekio al. 11, LT-10223 Vilnius, Lithuania \\ ${ }^{2}$ The Department of Management, Faculty of Business Management, \\ Vilnius Gediminas Technical University, Sauletekio al. 11, LT-10223 Vilnius, Lithuania \\ ${ }^{3,4}$ The Department of Business Technologies and Entrepreneurship, Faculty of Business Management, \\ Vilnius Gediminas Technical University, Sauletekio al. 11, LT-10223 Vilnius, Lithuania \\ *E-mail:k.peleckis@vgtu.lt
}

\begin{abstract}
Purpose - the purpose of the article is to examine how the extent of competition in the market affects the balance of bargaining powers of market participants. This often results in negative consequences for both buyers and suppliers. This study has important theoretical and practical implications. The authors made an analysis of existing theory and practice on negotiation strategies in a complex way, in accordance with levels of competition. Paper reveals the opportunities to develop and implement these strategies, taking into account market definition options.
\end{abstract}

Research methodology - the paper examines the application of Nash equilibrium to the preparation of negotiation strategies, looking at the function for the best result. The study would help to prepare business strategies for different competition levels.

Findings - the ways of preparation of negotiation strategies with different levels of competition, focusing on market definition opportunities.

Research limitations - there are not enough measures in international business negotiation theory helping to develop negotiation strategies in the face of distorted market competition and difficulties to define the market.

Practical implications - findings of the article will give opportunities for policymakers to develop and implement strategies for business negotiations.

Originality - the article consists presentation of new tools for negotiators in preparing negotiating strategies.

Keywords: competition, market, negotiation strategies, distorted market, monopoly, oligopoly.

JEL Classification: D41, D42, D43, F51.

Conference topic: Digitalization of Business Process: Trends, Challenges, Solutions.

\section{Introduction}

The extent of competition in the market affects the balance of bargaining power of market participants. This often results in negative consequences for both buyers and suppliers. More competition opens up opportunities for the development of international business, because, with more market participants, additional business alternatives appear, thus reducing the negative impact of distorted competition on the balance of negotiating power of international business negotiators. The article discusses the possibility of applying Nash equilibrium to the preparation of negotiation strategies, looking for the best result function.

The purpose of this article is to examine how the extent of competition in the market affects the balance of bargaining powers of market participants. This often results in negative consequences for both buyers and suppliers. This study has important theoretical and practical implications, in the first place, in the article is made an analysis of existing theory and practice on negotiation strategies in a complex way, in accordance of levels of competition. Secondly, to reveal opportunities to develop and implement these strategies, taking into account market definition options. The relevant market is usually determined using a hypothetical monopoly test (known as the SSNIP test), whereby the "market" covers all products and regions where the hypothetical profit monopoly reaches a small but significant price increase (Kaplow, 2018; OECD, 2012, 2016a; Ghosal \&Tonin, 2018). 
The paper examines the application of Nash equilibrium to the preparation of negotiation strategies, looking for the best result function. The study would help to prepare business strategies for different competition levels. The findings of the article offer ways of preparation of negotiation strategies with different levels of competition, focusing on market definition opportunities. However, there are some research limitations, as there is a lack of measures in international business negotiation theory helping to develop negotiation strategies in the face of distorted market competition and difficulties to define the market.

The findings of the article will give opportunities for policymakers to develop and implement strategies for business negotiations. The novelty of the article consists of the presentation of new tools for negotiators in preparing negotiating strategies.

\section{Theoretical approaches}

The market definition is widely used as an analytical basis for analyzing and evaluating competition concerns that have an impact on the preparation of negotiation strategies. The relevant market should be defined as that the competitive constraints faced by the company, that is, potential substitutes in the demand and supply areas would be captured as accurately as possible. The relevant market is usually determined using a hypothetical monopoly test (known as the SSNIP test), whereby the "market" covers all products and regions where the hypothetical profit monopoly reaches a small but significant price increase (Kaplow, 2018; OECD, 2012; Ghosal \& Tonin, 2018).

The market definition has several options for determining the extent of competition in the market, which is essential for preparing negotiation strategies. The main purpose of the market definition is to assess the existence, creation or strengthening of market power by describing the dynamics of market power parameters. Market power is defined as the ability of an enterprise to maintain a price higher than the long-term competitive price level (OECD, 2012; Liu, Wang, \& Chen, 2018; Schlosser, 2017; Kaplow, 2018; Kumar, 2018; Yasui \& Haraguchi, 2018; Chen \& Tanaka, 2018; Symeonidis, 2018, Uchiyama, 2018, Gámez, López, Rodríguez, Varga, \& Garay, 2018). The market shares of the undertakings concerned reflect their market power, which must be assessed in preparation of negotiation strategies.

Market definition facilitates the identification of relevant competitors and is useful for risk assessment for potential coordinated effects and mergers. In addition, defining the scope and coverage of competition it is also appropriate to examine other important competition issues, such as the investigation of potential barriers to market entry. Even in the absence of sufficiently detailed data for a hypothetical monopolistic test, the use of this test provides a consistent conceptual framework for defining the relevant market.

The importance of market definition is not only related to its role in analyzing competition issues: the concept is also used as a basis for calculating fines in order to assess the impact of EU Member States' trade between the EU Member States and as a procedural model for cross-cutting coverage (Schlosser, 2017; OECD, 2012). However, market definition is a difficult task and there are opinions that in some cases its suitability may be challenged (Kumar, 2018; OECD, 2012, 2015). The main concern is that even accurately calculated market shares and concentration in certain markets may be of limited value. In several types of markets, market shares and concentrations can be overestimated or underestimated by determining the market power of firms and the potential impact of competition.

For example, in differentiated product markets, the intensity of competition and product substitution is a more important indicator of market power than market share when assessing the impact of a merger. Similarly, in the bidding or auction markets, competition between participants is a more informative concept in merger cases. Market definition is difficult to apply in bilateral markets, which include platforms serving individual user groups, under indirect network effects. This is also true for industries that are experiencing rapid innovation, so the defined market boundaries may be unstable and may lead to rapid changes in market shares (Symeonidis, 2018; Schlosser, 2017; OECD, 2012).

In the case of monopolization or abuse of a dominant position, the assessment of market shares cannot be a very reliable indicator of market power if the company has already increased its prices significantly above the level of competition (Kaplow, 2018; OECD, 2012). In such cases of abuse of a dominant position, a detailed market definition is problematic, as the uncontrollable opposite price has to be used for market uncertainty. With current prices, the market will be defined too broadly, so it will not be feasible to determine situations when companies can take advantage of their influence on the markets. In view of these specific shortcomings in market definition, new measures have been developed (Kumar, 2018; OECD, 2012).

The first proposal was: the assessment of mergers with price pressure indices and other tools. For monopolization or abuse of dominant cases was suggested evidence of direct effects of anti-competitive practices or other compelling evidence of abuse. Price pressure indices have recently been developed as the first representation of merger analysis, especially when it comes to differentiated product markets. In the case of enlargement, the price pressure index (UPP) focuses on the merged entity's incentive to raise prices after the merger and is calculated using the referral ratio and profit margins before the merger. The UPP also takes into account the productivity achieved during the merger, which reduces the incentive to increase prices through standard data (Symeonidis, 2018; Kumar, 
2018; OECD, 2012). However, the UPP does not provide performance and size estimates for price increases. The overall price pressure index for development (GUPPI) is similar to the UPP but does not take into account its effectiveness (Kumar, 2018; OECD, 2012). The pricing indices can be combined with the demand function to quantify the price level after the merger, but the results are very sensitive to the form of the selected demand function and may be inaccurate. The proposed compensatory marginal cost reduction approach (CMCRs) is designed to avoid the need to define the curve of the demand curve, rather than focusing on the assessment of the required actuality by calculating the marginal cost reduction necessary to maintain the pre-transaction price. However, CMCR is intended for markets with price competition, and efficiency calculations are limited to cost-cutting analysis (Symeonidis, 2018; OECD, 2012). Other restrictions on price pressure indices are due to the fact that they are not considering possible supply dynamics and targeting metrics and margin measurement problems.

For example, comments from France and Korea show that it is difficult to gather reliable and accurate information on targeting indicators, taking into account operating restrictions by competition authorities. However, the available, albeit limited, empirical literature suggests that price pressure indices work well (Kumar, 2018; Schlosser, 2017; OECD, 2012). In addition to price pressure indices, especially under intense competition, other market definition tools may be used. Simplified versions of familiarization simulation models can be used for the initial review, and full models are often not used due to difficult data requirements and complexity of the application. Another recently developed method is a comparison of price and cost factors between the two products the price method for the assessment of possible substitutes (Kaplow, 2018; OECD, 2012). In cases where there is a monopoly and abuse of a dominant position, it has been proposed to bypass the definition of the relevant market and to establish a dominant position according to the direct effect of disputed behaviour. Although new tools have been created in order to eliminate the gaps in market definitions there are many markets, such as markets with quantitative competition, when for assessing market shares is applied the best available indicator. If evaluations are applied in cases where they have not been designed, then new tools can produce unreliable and perhaps inappropriate results (Kaplow, 2018; OECD, 2012). The ability to introduce new tools for this purpose varies across jurisdictions and depends on the specific type of law and executive system (Symeonidis, 2018; Kumar, 2018; OECD, 2012).

The definition of the market relates to legal certainty. New measures can strengthen the justice dimension. The application of additional or alternative measures may be more complicated in jurisdictions where the concept of market definition is deeply embedded in competition laws, because in order to abandon market definition it is necessary to amend or repeal legislation, unlike in jurisdictions that focus more on market power (Kumar, 2018; OECD, 2012). In the first case, the term "relevant market" may be set out in legislation, including primary sources of law, as well as provisions governing competition law. Definition determines the procedure for its application (Schlosser, 2017; OECD, 2012). Even if there is no legal requirement, the courts can oblige to determine case law for the definition of a relevant market (OECD, 2012). For example, where the jurisprudence has to prove a dominant position, the direct evidence of damage before analyzing anti-competitive activities cannot be a sufficient alternative to market definition. The possibility of setting new precedents in joint courts may be greater than in civil law systems based on the interpretation of the law.

The scope of judicial review is also important as competition authorities usually start to develop new tools, but the practice of competition authorities may be optional, and competition authorities and courts may be different (Kaplow, 2018; OECD, 2012). Judgments can be more perceived if the requirements for judicial review of market definitions are limited, such as in the case of the European Union (OECD, 2012). The legal consequences of withdrawing from the market definition in order to develop negotiation strategies, there may be greater uncertainty about the standards that will govern competition issues and the assessment of their results (OECD, 2012).

The market definition is used in almost all jurisdictions and is widely used for quite a long time. The fact that the market definition is relevant and if the market does not change very dynamically, market participants can make a more accurate self-assessment, as the market definition has priority (Kaplow, 2018; OECD, 2012). In contrast, the recently developed measures are specific and cannot be sufficiently matured, tested and empirically based on sound legal doctrines, a similar criticism has caused the market definition (Symeonidis, 2018; Kaplow, 2018; OECD, 2012). The existence of several methods allow for competition authorities to choose the most appropriate instrument in a particular case, but this freedom of choice is also a source of uncertainty, especially when different methods can produce conflicting results (Kumar, 2018; OECD, 2012). More and more jurisdictions are re-examining the role and importance of market definition and applying new methods to overcome its weaknesses and limitations.

In some jurisdictions it is emphasized that market definition is not the most important goal, it should not be the first step in any competition analysis and should not be applied in all cases (Schlosser, 2017; OECD, 2012). Instead of abandoning the market definition, most jurisdictions combine it with complementary methods. While generally considered to be a useful approach in all jurisdictions, a number of public authorities are increasingly reducing the importance of market definition and providing new approaches where the market definition is problematic. In this context, the BIAC report highlights the need for compatibility of international practice to reduce the risk of mismatches in the assessment of cross-border mergers and other cross-border business transactions (Kaplow, 2018; OECD, 2012). In some jurisdictions, competition authorities are already applying new measures to supplement or change the market definition (Kaplow, 2018; OECD, 2012). 
In 2010 the US Horizontal Merger Guidelines state that market definition is only one of many available damage assessment tools alongside more sophisticated economic instruments that are not based on the definition of a particular market for competition dynamics and stresses that the analysis of the impact of competition must not start with market definition. In addition, these revised guidelines allow the use of direct evidence of anti-competitive practices and provide a detailed description of the types of evidence accepted.

In the United Kingdom, the guidelines for the assessment of concentrations also reflect the transition from the definition of the relevant market to the analysis of the intensity of competition (Kumar, 2018; OECD, 2012). The use of new methods both in the United Kingdom and in the United States has created a mixed picture, which in some cases raises concerns about new measures.

Several other national competition authorities are also considering more and more new methods and measures, for example, in Ireland, the merger guidelines are currently under review. In almost all jurisdictions, a number of other important aspects, such as time zones or market entry barriers, development barriers, etc. are taken into account when analyzing competitive effects (Kaplow, 2018; OECD, 2012). Generally, the competition authorities tend to use new tools to complement, rather than replace market definition (Schlosser, 2017; Symeonidis, 2018; OECD, 2012). This additionality can be reinforced when the methodology applied and the data requirements for new instruments are similar to those relating to the market definition for price pressure indices. However, the clarity of procedures and technical solutions remains a challenge for many competition authorities. In addition, more research is needed to develop new tools to increase their reliability and the adequacy of performance measurement compared to the market definition indicator. Effective adaptation of new tools can also require skills and resources that are not currently available to competition authorities and professionals. In order to solve this problem, the competition authority, such as Norway, cooperate with the university in order to develop experience in applying new measures created an internal group to share knowledge about these new methods (OECD, 2012). The courts are also increasingly aware of the limitations of market definition (Kaplow, 2018; OECD, 2012). It should be noted that the recent rulings of the Court of Justice of the European Union are a transition to a less formal approach, which was characteristic of the early 1990s. The definition of a market is restrictive practices. In the United States, the courts sometimes use evidence of direct damage to assess the cooperation of their competitors. However, market definition is one of the most important analytical tools for analyzing and evaluating the competitive constraints faced by businesses as well as for assessing their impact on their competitive behavior (Kaplow, 2018; OECD, 2012). The specific market should be defined by competitive constraints: the balance between demand and supply, which should be captured as precisely as possible. The relevant market is usually determined by a hypothetical monopoly test, according to which the "market" covers all products and regions where the hypothetical maximum profit of the retailer has at least minimal impact on price increases. Market definition helps to determine the extent of competition in the market. The main purpose of the market definition is to assess the existence of market power, its ability to create or strengthen it. This can be described as the ability of the company to maintain a higher price in the long term competition. The market share of a particular company provides important knowledge of market power.

The market definition also helps to identify the relevant competitors and is useful in assessing the risk of potential exposure of business entities. In addition, competition concerns can be addressed by other relevant competition issues, for example, market access obstacles (Schlosser, 2017; OECD, 2012). Even when there is no data needed to perform a hypothetical monopolistic test, this test can serve as a consistent conceptual framework for defining the relevant market. The importance of market definition is not limited to competition problems: this concept is used as a basis for calculating fines in order to assess the impact on trade between the EU Member States, which is a model for other legislative processes.

However, market definition is a difficult task, and there are opinions that in some cases its validity may be questioned. The main concern is that even accurately calculated market shares and concentration in certain markets are limited. In markets, its parts and concentration measures may outweigh or underestimate the influence of companies on the market and the potential impact of competition.

For example, in different product markets, the intensity of competition and product substitution is a more important indicator of market power than market share when assessing the impact of a merger. Similarly, in the bidding or auction markets, competition between competitors is more informative for mergers. Thirdly, the market definition is difficult to apply in bilateral markets, which include platforms serving individual user groups under indirect network effects. Finally, industries with fast innovations but with defined market boundaries may be unstable and can rapidly change market shares. In the case of a monopoly or abuse of a dominant position, current market shares may be an unreliable indicator of market power if the company has already significantly exceeded its competitive level (Kumar, 2018; OECD, 2012).

Recently, price indices have been developed as the first tool for merger analysis. This tool is very important for analyzing differentiated product markets. However, price indices do not take into account the magnitude of the competitive impact. The rise in price pressures in the index analysis focuses on the merged entity's incentives to raise prices after the merger and is calculated using the referral ratio and profit margin levels before the merger. An account shall also be taken off the productivity achieved during the merger, which reduces the incentive to increase prices through a standard deduction. However, efficiency and price increases are not considered. 


\section{Research methodology}

The research methodology of the article consists of the examination of tools for analyzing differentiated product markets. On the analytical basis are evaluated the problems of competition have an impact on the preparation of the negotiation strategy. Market definition in formal under consideration cases by competition authorities is presented next to market competition assessment (Symeonidis, 2018; Kumar, 2018; OECD, 2016b). But accurate market definition application thresholds are unclear because it is difficult to tell when the market definition should be used as the basis for assessing competition (Kaplow, 2018; OECD, 2016b).

All the factors discussed in this article are relevant to the definition of the geographic market but most of them may also be related and with competitive assessment and competition authorities usually, decide whether to assess evidence on the basis of a geographic market definition or a competitive assessment or to assess either of these parameters. In general, and is expected to be certain duplication - a hypothetical monopolistic test of the geographic market definition is often simple and this may require a wide range of relevant evidence (Kaplow, 2018; OECD, 2016b).

The definition of the geographic market is an important and complex task, especially in terms of developing negotiation strategies. This describes the process of focusing on markets that may be wider than national borders. It also discusses how the geographic market definition is in line with competitive assessment and the tendency of some authorities to leave the definition in those cases when there is no problem related with competition (OECD, 2016b). The range of evidence is wide, which should be taken into account, in assessing the geographic scope of markets. Due to high price differences in all countries, there may be heterogeneity in conditions of competition, and thus a narrower definition of the market, however price analysis can also lead to misleading results. It may also be necessary to consider import flows and the dynamics of their evolution. However, this process can be speculative and some competition authorities are skeptical about them. Given the complexity of the use of price and import data, competition authorities and their specialists should also consider carefully the additional evidence. Despite the fact that they can be inseparable from product features, product characteristics, transport costs, regulatory and trade barriers, consumer preferences and market dynamics are playing an important role in forming the volume of the geographic market (Kumar, 2018; OECD, 2016b).

In the upcoming market definition tests, new challenges may arise. In particular, different jurisdictions have different approaches to foreign competition when assessing mergers. Although these differences do not seem to lead to fundamentally different decisions in different jurisdictions however, they may cause some uncertainty. Competition authorities should be alert to the fact that the definition of a geographic market that is too large (or unnecessary), may affect future interconnections and can hurt the efficiency on measures of competition remedies. This risk is particularly pronounced in the light of current market trends, which may mean that global market definitions (or at least global market statements from reporting countries) are increasing. Therefore, the authorities of different countries should be cautious and will use all available evidence in defining international geographic markets, even by way of cooperation. Merger reviews or the definition of the geographic market for antitrust proceedings may be a controversial issue (Kaplow, 2018; OECD, 2016b), as with the product market definition, the parties may be motivated to provide a geographical definition that would best minimize concerns about concentration or another impact of competitive behavior (often by defining the market as widely as possible). This can lead to disagreements with competition authorities, in particular when it is a probability that the market will expand beyond national borders. The competition authorities must carefully monitor decision-making, taking into account the broad market definition for future cases relating to the same market, for example, market definition as "global" rather than "regional", "continental" or others can significantly affect future merger approvals within and outside the jurisdiction of competition authorities (Kaplow, 2018; OECD, 2016b). Setting competition rules is an important process for competition authorities and professionals to evaluate the competitive effects of mergers or behavioral strength. The OECD has summarized this market definition process as follows (Symeonidis, 2018; OECD, 2016b):

"The market definition has several goals in determining the extent of competition in the market. The main purpose of market definition is to assess the presence, creation or strengthening of market forces, which is defined as the ability of the company to maintain a higher price than long-term competitiveness. Relevant firm market share shows its market power. The market definition also helps to identify relevant competitors and is useful in evaluating possible harmonized effects of merger risk. In addition, a setting area of competition can be examined other important competition issues, such as barriers of potential entry".

The market is defined in terms of both the product concerned and its geographical area (OECD, 2016b). Competition arena, which is affected by the merger may be geographically limited if geography limits the willingness or ability of some customers to replace certain products or the willingness or ability of some suppliers to serve some customers. This can affect both suppliers and customers. The guidelines state that geographic markets are usually based on the location of suppliers unless the suppliers can discriminate against consumers. In turn, the European Commission (EC) has highlighted the place of consumers, noting that "the market definition is essentially a customer-oriented task: to find out which alternative suppliers are relevant to customers in a particular area. If customers cannot rely on suppliers, located outside this area, the other suppliers are not part of the relevant geographic market"(Kaplow, 2018; OECD, 2016b). 
The most commonly used market definition tool is called the hypothetical monopolistic test (Symeonidis, 2018; OECD, 2016b). This test generally defines a geographic market as the smallest area in which a hypothetical monopolist could profitably determine a small but significant and uninterrupted increase in prices, exceeding the competitive price. In the distant territory would result in the narrowest area, where one business entity could profitably to fix for their customers the increase in prices by $5-10 \%$, because of:

- Customer's failure (or unwillingness) to travel to purchase from alternative stores outside the region;

-Failure of business entities to supply their customers outside the region.

In some high-tech industries having only a few manufacturers and complex users worldwide, the geographic market can be defined as global because a hypothetical monopolist in narrower geography could be unprofitable, because of possible substitutes from other foreign manufacturers (Kumar, 2018; OECD, 2016b).

\section{Research findings}

The competition authorities reviewing cases where there are no problems related to competition, without taking into account the geographic scope of the market, and the courts, often use an indicator of openness of geographic market definition (Symeonidis, 2018; OECD, 2016b). Keeping the geographic market definition open can save time and resources for competition authorities when they review mergers where there is no competition problem without assessing the geographic scope of the market. It also prevents authorities from seeking an unnecessary market definition that may affect future cases based on the superficial analysis (Kaplow, 2018; OECD, 2016b). However, this approach is not always the right choice - as mentioned above, it is limited to cases where no problems are found related to competition (OECD, 2016b). Without justifying the definition of the geographic market in controversial cases, which are related with bans or rights defence ways, these cases may be challenged in court, the actions of competition authorities may be associated with a lack of clarity in the assessment of the situation (Kaplow, 2018; OECD, 2016b). In addition, this approach can be criticized for perceived arbitrariness and uncertainty. If potential competitive pressure is marked by a change in demand (and hence a part of the market definition) or a potential entry barrier (and therefore not a market share), it should not be subject of General competitive assessment.

The analytical perception of the geographic market definition is similar to the product market definition, although the relevant evidence of the geographic market definition is somewhat unique (Symeonidis, 2018; OECD, 2016b). There is no reason to expect a dominant position to be assessed in cases of abuse, for example by including a different approach to the definition of the geographic market, except that it has completely refused to apply the impact-based approach as discussed in the OECD. It is important to consider criticism under which making decisions on abuse cases wrongly defines geographic markets taking into account the allegedly anti-competitive behaviour in the affected area but not to the extent of market competition (Kaplow, 2018; OECD, 2004, 2016b). However, the geographical area where anti-competitive behavior is taking place may sometimes be a good indicator to define the geographic market boundaries.

Review and analysis of price data is the first step in establishing a geographic market (OECD, 2016b) for example, price correlation analysis is sometimes used to prepare preliminary market descriptions before a complete hypothetical monopoly test quantitative implementation (if such implementation is possible). Justification of this approach is important because in the same geographic market for existing goods are applied equal conditions of competition (in line with EC guidelines) and thus price changes will be similar. Products with high prices may not put competitive pressure on each other and would therefore not be kept on the same market in terms of a hypothetical monopoly test (Symeonidis, 2018; OECD, 2016b).

This intuitive explanation suppresses the difficulties associated with making conclusions only from price evidence (Symeonidis, 2018; OECD, 2016b). For example, price data may be useful for conducting event investigations, seeking to examine the influence of price changes on import flows or margins. However, the possibility of such natural experiments on the market may be limited. In general, the limited amount of data available to competition is a serious obstacle to carry out a detailed analysis of the price.

Preparation and implementation of negotiation strategy may determine the future of a business entity, so before making strategically important decisions it is required comprehensive analysis of interests and needs of the parties involved in the future negotiations, which would allow a better understanding of the priorities of the other side of the negotiations, to assess the available negotiating power. This is especially true where distorted competition is in the market. Gaming theory techniques can help to achieve this because the gambling theory is a mathematical discipline that examines the interaction of objects with their own goals.

John Nash, who has successfully summed up the min-max theorem and confirmed that each competing game has at least one equilibrium point in both mixed and pure strategies. John Nash in 1951 in his scientific article has defined the equilibrium of non-linear gaming, which is now called Nash equilibrium and has introduced many strategic games with this equilibrium (Madeikyte, 2011). Nash is best known for his work in game theory. In mathematics, a game involves two or more "players" who earn rewards or penalties depending on the actions of all the participants. Some games are called zero-sum, which means that one player's gain is another player's loss. 
In 1950 was announced theorem proving the existence of Nash equilibrium in each of $n$ non-realistic gambling games. Nash equilibrium is widely applied in practice: to optimize networks, production plans and elsewhere (Madeikyte, 2011). John Nash gave his name to these equilibrium points, which are most widely used in the concept of gambling theory today. At the age of 21, he made a discovery that won him the Nobel Prize 1994 in Economics (along with Harsanyi and Selten).

Here is a mathematical description of the payout function (Figure 1).

The profit of a 1st business entity is:

$$
\pi_{1}\left(k_{1} ; k_{2}\right)=k_{1}\left(X\left(k_{1}+k_{2}\right)-c\right)=\left\{\begin{array}{c}
k_{1}\left(\alpha-c-k_{2}-k_{1}\right) \text { if } k_{1} \leq \alpha-k_{2} \\
-c q_{1} \text { if } k_{1}>\alpha-k_{2}
\end{array} .\right.
$$

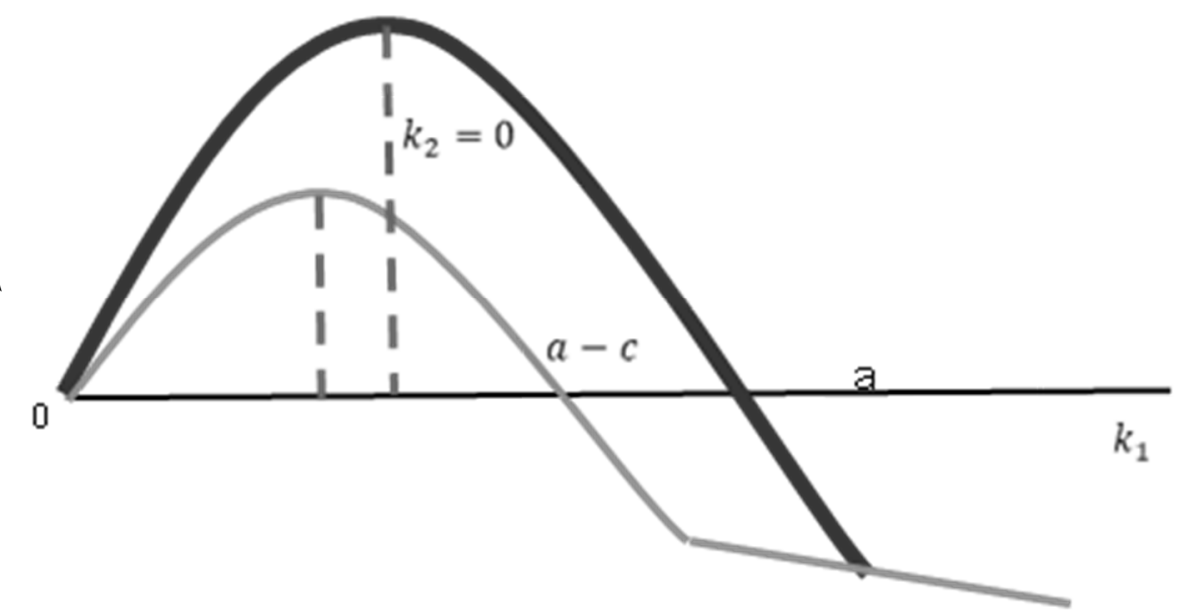

Figure 1. The best result functions (source: Madeikytè, 2011)

Nash's work was applied to non - cooperative games. In these situations, players may unilaterally change strategy to improve (or worse) their own outcome without affecting the other players. What Nash discovered is that any such game has a strategy, now called Nash equilibrium, where any unilateral change in strategy by a player results in a worse outcome for that player. Many scenarios in international relations may be modelled as noncooperative games. Nash equilibrium helps negotiators work out how competing companies set their prices, how governments should design auctions to squeeze the most from bidders and how to explain the sometimes selfdefeating decisions that groups make.

\section{Conclusions}

In the market definition, it is a widely used analytical basis to analyze and evaluate the problems of competition that have an impact on the preparation of the negotiation strategy. The relevant market should be defined in such a way that the competitive constraints faced by the company, that is substitutes of demand and supply side, would be captured as accurately as possible.

The definition of the geographic market is an important and complex task, especially in terms of preparing negotiating strategies. There is a described process of focusing on markets that may be wider than national borders. There is also discussion on how the geographic market definition is in line with the competitive assessment and the tendency of some authorities to leave the definition open in cases where there are no problems with competition.

The variety of evidence to be taken into account when assessing the geographic scope of the markets is wide. Because of the high price difference in all countries may appear heterogeneity of competitive conditions, and hence will be a narrower market definition, and price analysis can lead to misleading results. Keeping the open geographic market definition can be saved time and resources for competition authorities when they review mergers where there is no competition problem, regardless of the geographic scope of the market. It also prevents authorities from seeking an unnecessary market definition that may affect future cases based on a superficial analysis.

The geographical area, in which anti-competitive behavior is taking place, may sometimes be a good indicator outside the geographic market. Price data review and analysis is the first step in establishing a geographic market, for example, a price correlation analysis is sometimes used to prepare preliminary market descriptions against the quantification of a fully hypothetical monopoly test (if this is feasible). The rationale of this approach is that goods in the same geographic market subject to the same conditions of competition, with similar price changes. Products with 
high prices may not put competitive pressure on each other and would therefore not be kept on the same market for the purposes of a hypothetical monopoly test.

In the article were examined possibilities to adjust Nash equilibrium for preparing negotiation strategies seeking to find the function of the best result. The findings of the article will give opportunities for negotiators to develop and implement better strategies for business negotiations.

\section{Disclosure statement}

We declare that we do not have any competing financial, professional, or personal interests from other parties.

\section{References}

Chen, Y., \& Tanaka, M. (2018). Permit banking in emission trading: Competition, arbitrage, and linkage. Energy Economics, 71, 70-82. https://doi.org/10.1016/j.eneco.2018.01.032

Gámez, M., López, I., Rodríguez, C., Varga, Z., \& Garay, J. (2018). Game-theoretical model for marketing cooperative in fisheries. Applied Mathematics and Computation, 329, 325-338. https://doi.org/10.1016/j.amc.2018.02.017

Ghosal, S., \& Tonin, S. (2018). Noncooperative oligopoly in economies with infinitely many commodities and traders. Games and Economic Behavior, 109, 184-200. https://doi.org/10.1016/j.geb.2017.12.015

Kaplow, L. (2018). Price-fixing policy. International Journal of Industrial Organization, 61, 749-776. https://doi.org/10.1016/j.ijindorg.2017.12.008

Kumar, P. (2018). Market power and cost efficiencies in banking. International Journal of Industrial Organization, 57, $175-223$. https://doi.org/10.1016/j.ijindorg.2018.02.003

Liu, Q., Wang, L. F. S., \& Chen, C. L. (2018). CSR in an oligopoly with foreign competition: Policy and welfare implications. Economic Modelling, 72, 1-7. https://doi.org/10.1016/j.econmod.2018.01.002

Madeikytė, N. (2011). Tiesiniai modeliai Nešo pusiausvyrai rasti. Iš 14-oji Lietuvos jaunujų mokslininku konferencija „,Mokslas Lietuvos ateitis “, 2011 metų teminès konferencijos straipsnių rinkinys, 1-4.

OECD. (2004). Factsheet on how competition policy affects macro-economic outcomes. Retrieved from http://www.oecd.org/daf/competition/

OECD. (2012). Market definition. DAF/COMP(2012)19. Retrieved from http://www.oecd.org/daf/competition/Marketdefinition2012

OECD. (2014). Recommendations for combating bid falsification in public procurement. Retrieved from http://www.oecd.org/daf/competition/RecommendationOnFightingBidRigging2012

OECD. (2015). Competition enforcement in oligopolistic markets. DAF/COMP. Retrieved from http://www.oecd.org/daf/competition/

OECD. (2016a). Competition assessment toolkit. Principles. Retrieved from https://www.oecd.org/daf/competition/42228385

OECD. (2016b). Defining geographic markets across national borders. DAF/COMP/WP3(2016)5. Retrieved from http://www.oecd.org/daf/competition/geographic-market-definition

Schlosser, R. (2017). Stochastic dynamic pricing and advertising in isoelastic oligopoly models. European Journal of Operational Research, 259(3), 1144-1155. https://doi.org/10.1016/j.ejor.2016.11.021

Symeonidis, G. (2018). Collusion, profitability and welfare: Theory and evidence. Journal of Economic Behavior \& Organization, 145, 530-545. https://doi.org/10.1016/j.jebo.2017.11.010

Uchiyama, T. (2018). Quasi-competitiveness in the Cournot model with heterogeneous firms. Economics Letters, 165 , $62-64$. https://doi.org/10.1016/j.econlet.2018.02.006

Yasui, Y., \& Haraguchi, J. (2018). Supply function equilibria and nonprofit-maximizing objectives. Economics Letters, 166, 5055. https://doi.org/10.1016/j. econlet.2018.02.008 